\title{
ANÁLISE DE FAVORABILIDADE PARA A EXPLORAÇÃO DE ÁGUA SUBTERRÂNEA NA REGIÃO DO MÉDIO TIETÉ, ESTADO DE SÃO PAULO.
}

\author{
ALEXANDRE CAMPANE VIDAL ${ }^{1}$, SIDNEI PIRES ROSTIROLLA ${ }^{2} \&$ CHANG HUNG KIANG ${ }^{3}$
}

\begin{abstract}
ANALYSIS OF FAVORABILITY FOR GROUNDWATER EXPLORATION IN THE MIDDLE TIETE VALLEY, SÃO PAULO STATE, BRAZIL Favorability analysis has been applied as a method to reduce the exploratory risk in groundwater exploration. The analysis was carried out in the outcropping areas of Tubarão Group, between the cities of Campinas and Sorocaba. The study area was chosen because of its geological complexity and the consequent lower predictability of well behavior before drilling. To apply this method, we considered as "mineralized" areas those regions with highest specific capacity values, taking also into account variables such as sandstone percentage, faults distribution, field altitude and electrical conductivity. The results demonstrate that the region encompassing the Tietê city and that between the cities of Elias Fausto and Monte Mor present the best potential for groundwater exploration.
\end{abstract}

Keywords: favorability analysis, hydrogeology.

Resumo Este estudo aplica a análise de favorabilidade para a exploração de água subterrânea, visando a diminuição do risco exploratório. A análise foi realizada na área de afloramento do Grupo Tubarão, entre os municípios de Campinas e Sorocaba. A definição para a utilização desta área se deve à alta complexidade geológica, que acarreta na baixa previsibilidade quanto ao comportamento dos poços antes da perfuração. Para a implantação desta metodologia, foram adotadas como áreas "mineralizadas" aquelas com os maiores valores de capacidade específica. As variáveis utilizadas foram a porcentagem de arenitos, distribuição dos lineamentos, altitude do terreno e condutividade elétrica da água subterrânea. Os resultados obtidos destacaram uma grande área entre os municípios de Tietê e Mombuca e as regiões de Elias Fausto e Monte Mor, como de melhor potencial para exploração de água subterrânea.

Palavras-chave: análise de favorabilidade, hidrogeologia.

INTRODUÇÃO O sucesso na exploração de água subterrânea está vinculado ao grande número de variáveis, relacionadas a fatores geológicos, ao método e qualidade do equipamento utilizado na perfuração e a finalidade de construção de determinado poço. De forma geral, o fator geológico pode ser considerado fundamental, pois a impossibilidade geológica de determinada área impede qualquer planejamento exploratório de água subterrânea.

O desenvolvimento de métodos estatísticos que objetivam a análise de incertezas tem sido destinado a várias áreas da exploração mineral (Rostirolla et al. 2003, Harbaugh et al. 1995). Para a exploração de água subterrânea, a estatística bayesiana é muitas vezes utilizada para a análise de incertezas de parâmetros hidrológicos de pequena escala, visando a calibração de modelos de simulação de fluxo (Feyen et al. 2003, Feyen et al. 2002).

O objetivo deste trabalho é a aplicação da análise de favorabilidade, um método baseado na estatística bayesiana, para definição das áreas mais favoráveis à exploração de água subterrânea e determinação das variáveis que possuem maior peso na definição das áreas de exploração.

A análise de favorabilidade é uma metodologia estatística utilizada para indicar a existência de depósitos minerais ou de acumulações de petróleo, embasada na ponderação e associação espacial de dados geológicos e geofísicos, com fins exploratórios. O propósito desta avaliação é discriminar as regiões com melhores chances para descobertas, possibilitando priorizar sub-áreas para trabalhos de prospecção (Rostirolla 1996).

Com base no estudo da distribuição espacial e coexistência entre variáveis e depósitos, o sistema de avaliação proposto torna possível inferir quanto e de que modo cada variável mapeada está associada ao processo mineralizador e, conseqüentemente, em que grau indica a existência de um bem mineral.

O método estatístico bayesiano consiste em determinar a probabilidade de ocorrer um dado evento, de acordo com um condicionante, como por exemplo, a probabilidade de ocorrer um depósito não descoberto a partir da existência de alguns atributos geológicos mapeados.

Como área de estudo foi definida a região aflorante do Sistema Aquífero Tubarão, na porção central do Estado São Paulo. Esta área é caracterizada por baixa condutividade hidráulica e fraco potencial produtivo (Diogo et al. 1981, DAEE, 1981a, b).

A crescente demanda por água subterrânea na área de pesquisa e a grande heterogeneidade geológica presente nestes sedimentos, faz com que a análise de favorabilidade se torne uma importante ferramenta para a quantificação da incerteza exploratória e o melhor gerenciamento deste sistema aqǘ́fero.

MÉTODOS Na análise de favorabilidade, ao invés de analisar isoladamente cada variável amostrada, os atributos georeferenciados são discretizados em células e correlacionados espacialmente, resultando nos mapas de favorabilidade.

A combinação das informações de diversos níveis é utilizada para gerar uma saída de dados que permita ao geólogo calcular um determinado valor, tal como a probabilidade de ocorrer um depósito.

A etapa inicial da avaliação corresponde à montagem do modelo

I - UNICAMP/IG/Departamento de Geologia e Recursos Naturais. R. Pandiá Calógeras, 51 CEP: 13083-970 Caixa Postal: 6152 Campinas-SP. e-mail: vidal@ige.unicamp.br

2 - UFPR/ Departamento de Geologia. Caixa Postal 19011 CEP81.531-990. Curitiba, PR. e-mail: rostirolla@ufpr.br

3 - UNESP/IGCE/Departamento de Geologia Aplicada. Caixa Postal 178. CEP 13.506-900. Rio Claro, SP. e-mail: chang@rc.unesp.br 
de ocorrência, quando são discriminadas as evidências favoráveis à concentração (critérios diagnósticos). A segunda etapa consiste na geração de um modelo de probabilidade, estruturado segundo o modo de ocorrência. Assim, é possível predizer a favorabilidade de um depósito ou de uma acumulação, de tamanho e volume adequados, ocorrer em determinada área alvo.

Seguindo as premissas presentes em Rostirolla et al. (1997), são consideradas "necessárias" aquelas variáveis que sempre existem nos depósitos conhecidos, enquanto as variáveis "suficientes" podem ou não existir, mas a sua ocorrência representa um forte indício de mineralização. A condição de suficiência de uma variável $E$ é satisfeita quando a probabilidade de existência do depósito (hipótese $H$ ) é maximizada com a presença da variável $(\mathrm{P}(H \mid E)=$ máximo). A condição de necessidade da variável é satisfeita quando a probabilidade de não existência do depósito é maximizada com a ausência da variável (P $\bar{H} \mid \bar{E}=$ máximo).

Nos mapas de variáveis exploratórias, os pontos conhecidos (amostras da população estudada) são tratados como pixels e estimados espacialmente. A probabilidade condicional é obtida através do número de pixels da variável inserido na área mineralizada, em relação ao número total de pixels existente da variável.

Segundo o modelo adotado por Bonham-Carter (1994), em todas as células avaliadas, a chance posterior $C h\left(H \mid E_{j}^{k}\right)$ de ser encontrado um depósito (ou hipótese $H$ ) é dada pelo somatório da chance prévia $\mathrm{Ch}(H)$, obtida da razão entre o número de pixels da área mineralizada pelo número de pixels da área de estudo, com os ponderadores $w_{j}^{k}$ referentes às evidências $E_{j}^{k}$ :

$$
\ln C h\left(H \mid E_{j}^{k}\right)=w_{j}^{k}+\ln C h(H)
$$

onde o índice superior $k$ refere-se à presença (+) ou ausência (-) da variável, e os ponderadores $w_{j}^{k}$ são razões de probabilidade (likelihood ratios) calculados do seguinte modo para cada variável $E_{j}^{k}$ :

$$
w_{i}^{k}=\ln \frac{P\left(E_{j}^{k} \mid H\right)}{P\left(E_{j}^{k} \mid \bar{H}\right)}=\ln \frac{\frac{H \cap E_{j}^{k}}{\bar{H} \cap E_{j}^{k}}}{\frac{H}{H}}
$$

Todos os níveis georeferenciados adicionais devem ser computados como mapas binários e, para $E_{j}(j=1,2,3, \ldots \mathrm{n})$ mapas, o somatório é representado pelas fórmulas:

$\ln C h\left(H \mid E_{1}^{k} \cap E_{2}^{k} \cap \ldots \cap E_{n}^{k}=\sum_{j=1}^{n} w_{j}^{k}+\ln C h(H)(3)\right.$
$C h\left(H \mid E_{1}^{k} \cap E_{2}^{k} \cap \ldots \cap E_{n}^{k}\right)=\exp \left\{\sum_{j=1}^{n} w_{j}^{k}+\ln C h(H)\right\}(4)$

Baseado nos resultados, a probabilidade posterior (ou favorabilidade para cada célula avaliada) pode ser obtida a partir da chance posterior (equação 4).

Para a aplicação da análise de favorabilidade na exploração de água subterrânea, serão adotadas como condição de sucesso as maiores produtividades nos poços, verificadas através dos valores de capacidade específica, obtidas quando a vazão é dividida pela diferença entre nível dinâmico e nível estático. Esta medida corresponde à quantidade de água retirada do poço por unidade de tempo e de rebaixamento.

A vazão nos poços é influenciada pelas características físicas do reservatório e também pelos métodos adotados para sua construção, como por exemplo, diâmetro da tubulação, número de intervalo com filtros e qualidade do equipamento utilizado.
De forma simplista, segundo a equação fundamental de Darcy, o fluxo do aquíf́rero é influenciado diretamente pelo gradiente e condutividade hidráulica. O gradiente hidráulico é responsável pelo diferencial de pressão que atua no direcionamento do fluxo da água subterrânea e a condutividade hidráulica pela melhor condição de fluxo.

Em rochas sedimentares siliciclásticas, as melhores condições de fluxo ou de condutividade hidráulica estão relacionadas às rochas de maior granulometria e grau de seleção, usualmente encontradas em arenitos "limpos".

Para a confecção dos mapas necessários à análise de favorabilidade foi utilizada a base de dados presente no trabalho de Vidal (2002). Esta base conta com a catalogação de 1.268 poços referentes a vazão, nível estático e nível dinâmico, além de 1.051 com descrições litológicas e 90 com análises físico-químicas.

A etapa inicial para o desenvolvimento da análise de favorabilidade foi a padronização da dimensão dos mapas a serem utilizados. A malha definida foi de 49 × 50 blocos, com área total de $4.418,5 \mathrm{~km}^{2}$ e área do bloco de $2,62 \mathrm{~km}^{2}$.

Na aplicação da análise de favorabilidade, foi definido como sucesso na exploração de água subterrânea as regiões que apresentaram maiores valores de capacidade específica nos poços.

O mapa de capacidade específica foi realizado com a utilização de 1.268 poços, o que permitiu a visualização da distribuição dos valores de capacidade específica para a área de estudo.

Para este trabalho, foram consideradas as "áreas mineralizadas" relacionadas aos maiores valores de capacidade específica, correspondentes ao quartil superior. Com isso, foram definidas no mapa as áreas com valores de capacidade específica superior a $0,52 \mathrm{~m}^{3} / \mathrm{h} / \mathrm{m}$.

ÁREA DE ESTUDO A área de estudo corresponde à região aflorante do Grupo Tubarão na porção central do Estado de São Paulo, limitada a leste pelas rochas do embasamento cristalino, a oeste pelos sedimentos do Grupo Passa Dois e, a norte e sul, respectivamente, pelos paralelos $22^{\circ} 45^{\prime}$ e $23^{\circ} 20^{\prime}$ de latitude sul, perfazendo área aproximada de $4.350 \mathrm{~km}^{2}$. Os poços da base de dados apresentam distribuição irregular com maior concentração na região nordeste e próximo aos principais municípios da região (Fig. 1).

O Grupo Tubarão é formado por rochas sedimentares neopaleozóicas da base da Bacia do Paraná, subdividido entre o Subgrupo Itararé, constituído por sedimentos depositados em condições glaciais, e a porção superior, composta por sedimentos pós-glaciais correspondentes à Formação Tatuí.

Os sedimentos correspondentes ao Subgrupo Itararé estão presentes na quase totalidade da área de pesquisa, sendo que a Formação Tatuí ocorre em estreita faixa a oeste.

França \& Potter (1989) adotam o status de Supergrupo Tubarão, dividido em Grupo Itararé e Grupo Guatá, considerando dados de toda a Bacia do Paraná. No Estado de São Paulo, a unidade estratigráfica Itararé permanece indivisa na maioria dos trabalhos, recebendo com isso a denominação de Subgrupo Itararé.

Os problemas encontrados para a subdivisão do Subgrupo Itararé se traduzem na falta de continuidade lateral dos corpos rochosos e de camadas guias nesta unidade. Esta situação está condicionada, em parte, à variabilidade dos ambientes de sedimentação que ocasionaram a alta heterogeneidade geológica deste conjunto de rochas (França \& Potter 1989, Caetano-Chang 1984, Fúlfaro et al. 1984).

A variabilidade geológica encontrada nestes sedimentos tem 


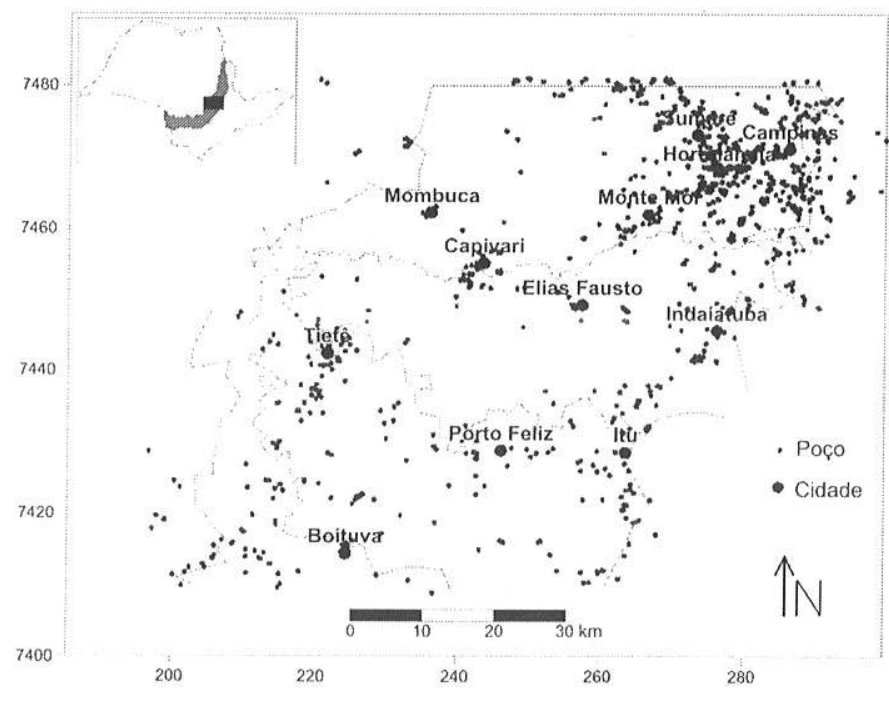

Figura I - Mapa de localização, com indicações dos poços presentes na base de dados. O quadrado no alto esquerdo da figura indica a área de ocorrência do Grupo Tubarão no Estado de São Paulo e o limite da área de estudo em preto.

reflexo direto no comportamento do fluxo no aquífero. Segundo Stevaux et al. (1987), o comportamento errático dos sedimentos arenosos, a distribuição irregular dos poços e o pequeno número de informações em relação à grande heterogeneidade, são as principais causas para a elevada incerteza na prospecção de água subterrânea na região. Além disso, os depósitos do Grupo Tubarão são cortados, em diversos pontos, por intrusões de diabásio que localmente, ou mesmo regionalmente, interrompem a continuidade da rocha reservatório.

Com base na distribuição de arenitos, o Subgrupo Itararé no Estado de São Paulo pode ser dividido em três unidades: inferior e superior, mais arenosas e com espessura aproximada de 200m; e unidade média, onde predominam sedimentos finos, com espessura de 200 a $500 \mathrm{~m}$ (DAEE-UNESP 1979).

A porção inferior ocorre em estreita faixa junto ao embasamento da bacia, sendo predominantemente arenosa, apresentando arenitos conglomeráticos e ritmitos. A unidade média, de maior extensão, ocorre no centro da área aflorante e apresenta diamictitos de matriz lamítica, arenitos finos e pelitos. A unidade superior apresenta maior ocorrência junto à borda oeste, constituída principalmente por arenitos grossos e diamictitos de matriz arenosa (Fig. 2).

A geometria dos aquíiferos é influenciada, em termos regionais, pela disposição das unidades arenosas presentes no Subgrupo Itararé. Segundo a classificação do Diogo et al. (1981), as unidades Superior e Inferior apresentam as melhores condições de exploração.

Steavux et al. (1987) analisaram o Subgrupo Itararé na bacia do Rio Capivari e sugeriram um modelo para prospecção de água subterrânea determinando três tipos de aqüíferos: (1) arenitos conglomeráticos e arenitos grossos de leques aluviais, com vazões entre 1 e $5 \mathrm{~m}^{3} / \mathrm{h}$; (2) sedimentos arenosos de frente deltaica, com vazões médias de $35 \mathrm{~m}^{3} / \mathrm{h}$; (3) sedimentos arenosos de geometria tabular e de grande extensão, com vazões que chegam até $100 \mathrm{~m}^{3} /$ h.

Estudos detalhados das condições de fluxo do aqüífero foram realizados por vários autores (Yoshinaga-Pereira 1996, IG/SMA 1995, Lopes 1994, IG/SMA 1993). Estes trabalhos apontam a grande variabilidade dos valores de capacidade específica, com valores médios que variam de 0,09 a $1,32 \mathrm{~m}^{3} / \mathrm{h} / \mathrm{m}$, e a influência dos corpos de diabásio sobre o comportamento do fluxo dos aqüíferos.

Do ponto de vista hidroquímico, o Sistema Aqüífero Tubarão é caracterizado por conter águas fracamente salinas e classificadas como bicarbonatadas sódicas e cálcicas (Campos 1993, Diogo et al., 1981; DAEE, 1981a,b; Taltasse, 1968).

Além da baixa salinidade, o pH varia de ácido a básico, com valores entre 4,8 e 9,0. O bicarbonato é predominante entre os ânions, podendo atingir $285 \mathrm{mg} / \mathrm{L}$. Entre os cátions, predominam o cálcio e o sódio, com valores que variam de 0,0 a 46,4 mg/L e de 0,1 a $170 \mathrm{mg} / \mathrm{L}$, respectivamente.

Os teores de resíduo seco variam entre 21 a $421 \mathrm{mg} / \mathrm{L}$ e a distribuição espacial destes valores indica tendência geral de enriquecimento no sentido da drenagem superficial.

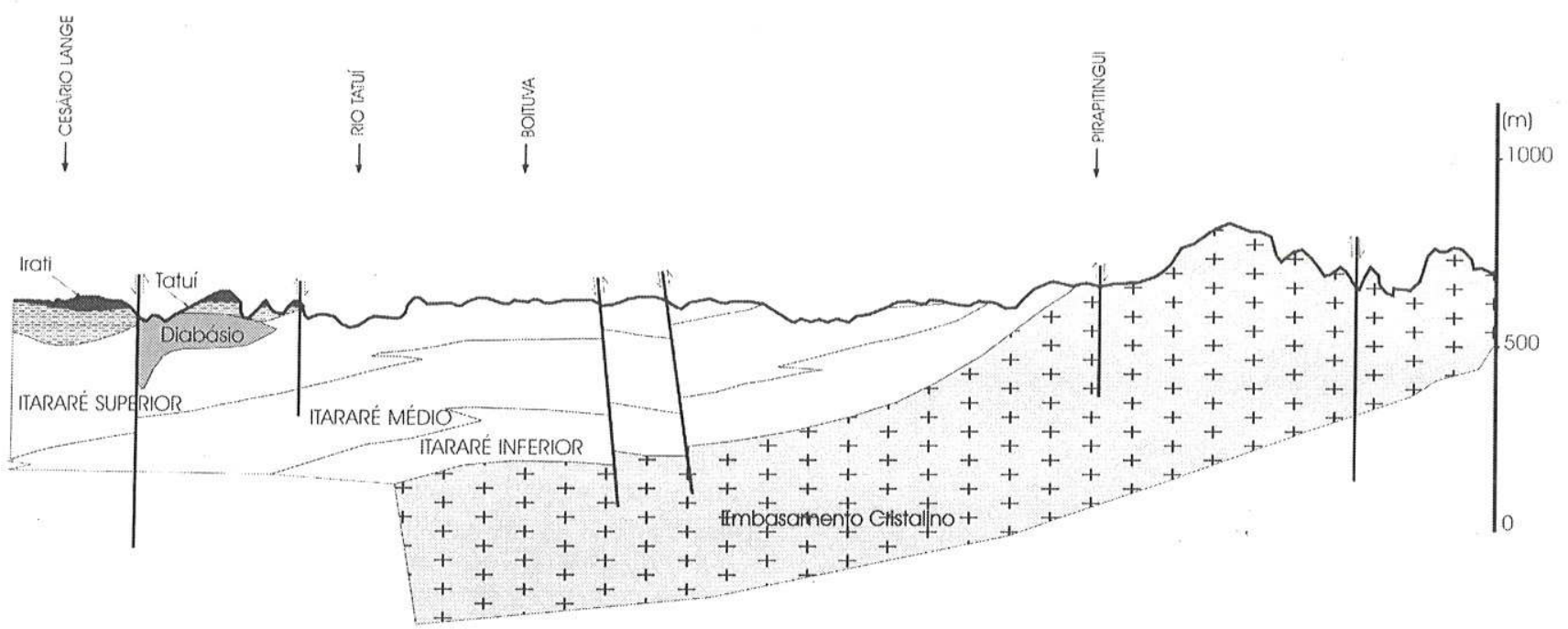

Figura 2 - Perfil litológico da região sul da área de estudo (modificado de DAEE 198Ib). 
das águas no aqüífero, ocorrendo o inverso para a região de descarga.

Distribuição dos Lineamentos A presença de falhas é considerada como outro fator de aumento da permeabilidade em aquíferos, esta relação entre presença de falhas e maior vazão nos poços pode ser melhor verificada na região de Campinas (YoshinagaPereira 1996, IG/SMA 1993, IG/SMA 1995).

O mapa dos principais lineamentos foi traçado através da análise de imagens de satélite Landsat 7-ETM, Modelos Digitais do Terreno (SRTM) e mapas geológicos (DAEE-UNESP 1979). A superposição de eventos pode ser identificada através da análise dos sensores remotos, onde são observados comportamentos diferenciados nos conjuntos litológicos e concentração de elementos estruturais em direções específicas. A análise morfoestrutural iniciou-se com o traçado de lineamentos em imagens SRTM nas escalas 1:750.000 a 1:300.000, posteriormente refinadas com a interpretação de imagens Landsat 7 nas escalas 1:300.000 a 1:100.000, resultando em feições estruturais representativas de zonas de falhas regionais.

O mapa apresenta os principais lineamentos com predomínio da direção NE-SW, relacionadas às falhas normais de borda da bacia, subordinadamente, ocorrem lineamentos com direção NWSE (Fig. 4d).

Diferente das outras variáveis, a distribuição dos lineamentos é uma variável discreta, por isso foi considerado valor igual a I na intersecção das áreas mineralizadas com zonas de falhas, e igual a zero, quando não há intersecção.

Para ilustrar a posição dos teores de corte definidos para as variáveis contínuas em relação com as áreas mineralizadas, foram criados histogramas com a distribuição das variáveis, separadas pelas células do grid posicionadas na área mineralizada e não mineralizada (Fig. 5).

Nos histogramas é possível observar a relação entre as áreas mineralizadas e os maiores valores de condutividade elétrica e porcentagem de arenitos, e os baixos valores de cota altimétrica.

Porém, apesar da tendência descrita para cada teor de corte, as distribuições das variáveis entre as áreas mineralizadas e não mineralizadas apresentam grande dispersão dos dados, o que explica a dificuldade para a definição dos teores de corte para a exploração de água subterrânea.

Mapa de favorabilidade Para o cálculo dos pesos $\left(w^{+}\right.$e $w^{-}$da equação 2) para as variáveis selecionadas foi utilizado o algoritmo proposto por Bonham-Carter (1994). Estes pesos são os atributos mais importantes na análise de favorabilidade: quanto maior for a diferença entre $w^{+}$e w' ou o contraste " $C$ ", mais correlacionável é a variável com a área mineralizada (Tabela 1 ).

Os resultados do cálculo dos pesos apontam valores de contraste "C" superiores a 0,5 , o que indica a boa relação entre todas as variáveis com as áreas mineralizadas.
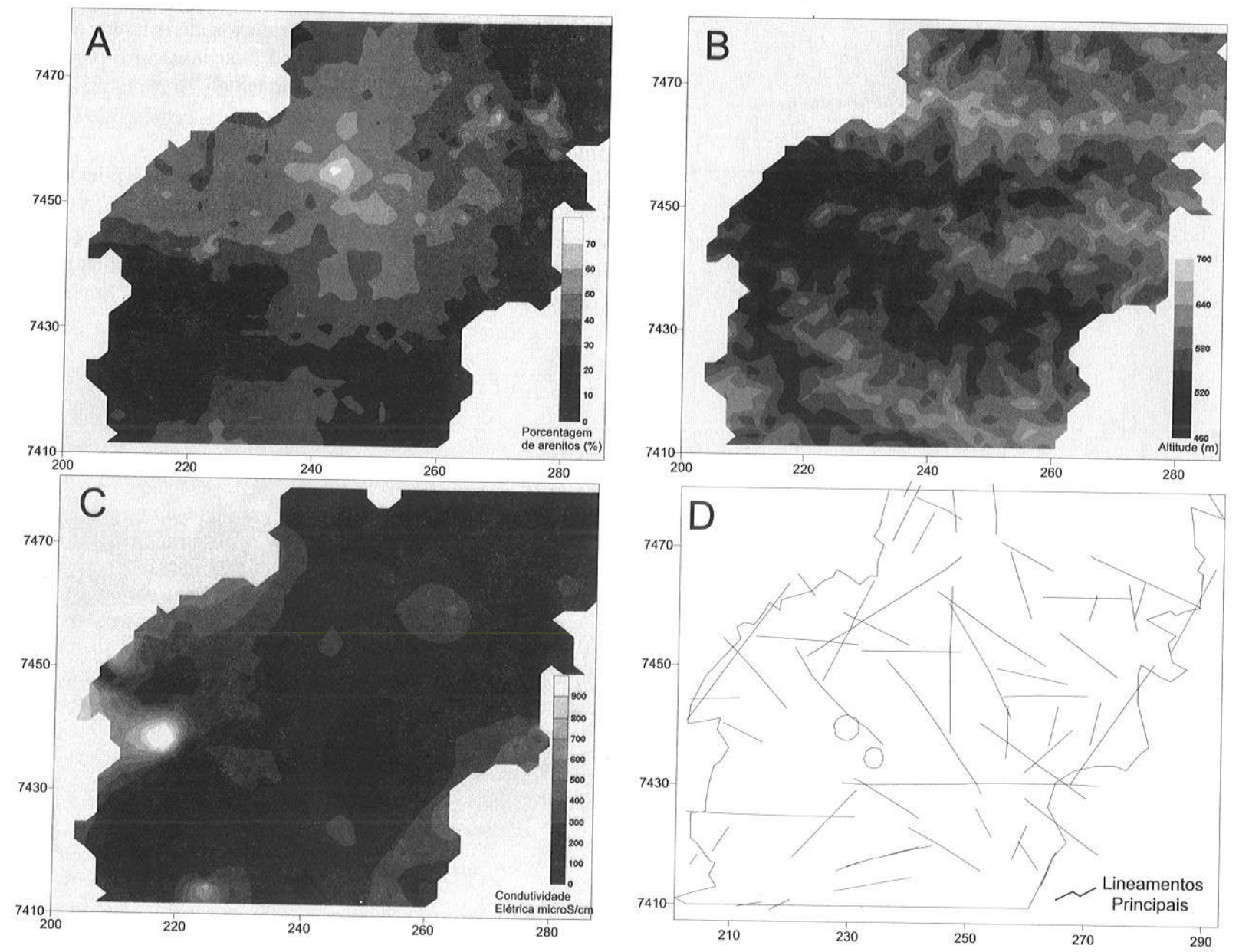

Figura 4 - Mapas das variáveis selecionadas para a análise de favorabilidade. A - Porcentagem de Arenitos, B - Cota altimétrica do terreno, C-Condutividade elétrica da água, D-Distribuição dos principais lineamentos. 
A condutividade elétrica é a variável que apresenta a maior correlação com a produtividade dos poços. Isto indica que as áreas de recarga, de baixa salinidade, têm pouca probabilidade de apresentarem boas condições de vazões nos poços. Como esperado, as áreas de descarga, posicionadas na região oeste e junto às drenagens, são mais favoráveis (Tabela 1).

Em escala regional, o comportamento livre do aquíf́ero, descrito por vários autores, pode ser confirmado pela boa correlação com a cota altimétrica do terreno, aliada à boa correlação com a salinidade do aqüífero.

Para a confecção do mapa de favorabilidade, foram utilizadas todas as variáveis descritas, uma vez que os valores de contraste foram superiores a 0,5 . Situação de descarte de alguma variável ocorreria se os pesos apresentassem valores muito próximos e, portanto, valor de contaste próximo a zero.

A probabilidade posterior foi então calculada através da soma dos pesos das variáveis para cada célula, mais a probabilidade a

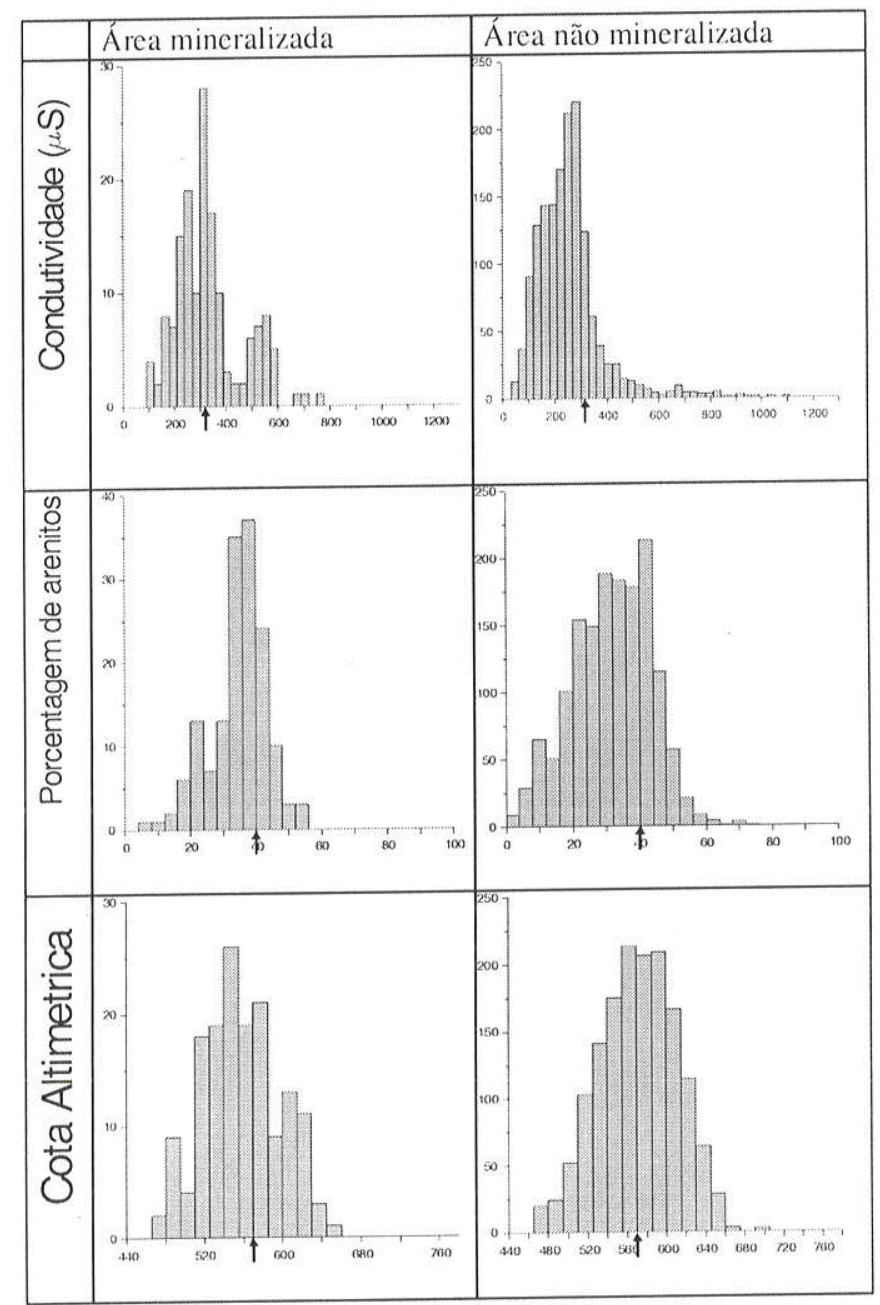

Figura 5 - Histogramas referentes às variáveis porcentagem de arenitos, condutividade elétrica e cota altimétrica do terreno, separados pelos valores dentro e fora das áreas mineralizadas. Nota-se sutil diferença entre os histogramas, demonstrando a dificuldade para a definição do teor de corte. As setas em preto indicam o posicionamento do teor de corte para cada variável.
Tabela 1 - Pesos definidos para as variáveis utilizadas.

\begin{tabular}{lccc}
\hline \multicolumn{1}{c}{ Análise Bayesiana } & $\mathrm{w}^{+}$ & $\mathrm{w}^{-}$ & $\mathrm{C}$ \\
\hline 1- Altitude do terreno & 0,52 & $-0,053$ & 0,573 \\
2- Porcentagem de arenitos & 0,80 & $-0,09$ & 0,89 \\
3- Condutividade elétrica & 1,31 & $-0,18$ & 1,49 \\
4- Falhas & 0,67 & $-0,08$ & 0,75 \\
\hline
\end{tabular}

priori (Equação 4). Os resultados obtidos de cada célula foram plotados em mapa, que apresenta as áreas mais favoráveis à exploração de água subterrânea correspondente aos maiores valores de probabilidade posterior (Fig. 6).

No mapa de favorabilidade, a maior probabilidade de sucesso está posicionada na porção oeste e centro-oeste da área de estudo, entre os municípios de Tietê e Mombuca, e secundariamente, nas regiões de Capivari, Elias Fausto e Monte Mor. As áreas mais favoráveis à exploração apresentam as maiores porcentagens de arenito, presença de falhamentos, baixa altitude do terreno e valores de salinidade mais elevados.

Por outro lado, condições menos favoráveis se encontram na região NE, área referente aos municípios de Campinas, Hortolândia e Sumaré, e na região S-SW, entre os municípios de Boituva, Itu e Porto Feliz.

Ao realizar a comparação entre os mapas de favorabilidade e de capacidade específica (Fig. 2) é possível constatar que, através das variáveis utilizadas e dos pesos atribuídos a estas, a área de Tietê é de alto potencial para exploração. Entretanto, a região de elevada capacidade específica em Elias Fausto foi parcialmente identificada, e no caso da área a norte de Boituva as diferenças foram maiores. O inverso ocorreu para as regiões de Capivari e Monte Mor.

As dificuldades encontradas para a aplicação deste método indicaram ser necessário um melhor desenvolvimento na definição dos critérios de teor de corte. Isto poderia se iniciar com a separação da base de dados pelos tipos de poços e, assim, realizar a análise de favorabilidade, visando determinar áreas para exploração de

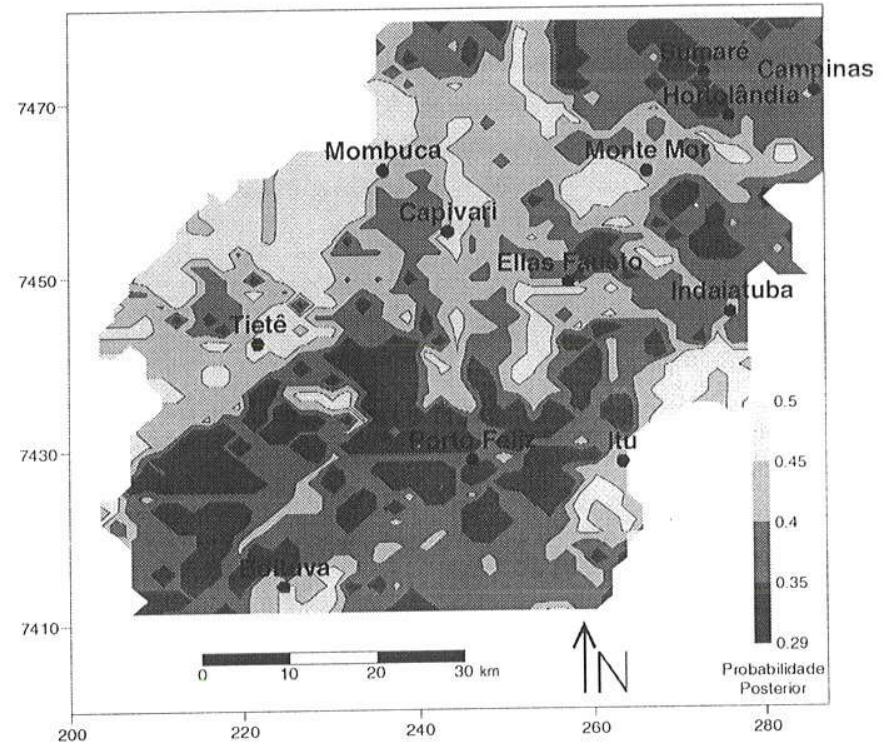

Figura 6- Mapa de favorabilidade bayesiana para a área de estudo. 
água subterrânea para condições mais específicas.

É necessário ressaltar que o comportamento do fluxo no aqüífero, para a escala utilizada, é um processo de alta complexidade e que obviamente a precisão dos resultados não será fornecida por apenas 4 variáveis. Por isso é de fundamental importância o incremento de novas variáveis, como a utilização de atributos relacionados à rocha reservatório em três dimensões, ao efeito da diagênese, a espessura do pacote sedimentar e conectividade entre os corpos de arenitos.

Todo o desenvolvimento desta metodologia é realizado em função dos mapas da área mineralizada e das variáveis, a utilização de métodos geoestatísticos para diminuição dos erros de estimativa certamente terão grande influência nos resultados obtidos.

CONCLUSÕES A análise de favorabilidade aplicada para o aqüífero Tubarão na região afloramento da região do médio Tietê comprovaram a região entre Tietê e Mombuca como de alto potencial exploratório, enquanto que outras áreas com elevada vazão foram parcialmente identificadas. As áreas de baixo valor de capacidade específica à nordeste e sudoeste foram confirmadas como de baixo potencial.

Parte dos desvios no resultado poderá ser reparada com o incremento de outras variáveis e com a utilização de métodos de interpolação que diminuam o erro de estimativa nos mapas. No entanto, a principal dificuldade está na definição do teor de corte para as variáveis utilizadas, em outras palavras, quais os limites de cada variável que implicariam na impossibilidade de exploração de água subterrânea.

Agradecimentos À estudante Maria Luiza Martini pela colaboração na confecção do mapa dos principais lineamentos e aos revisores da RBG pelas sugestões ao original.

\section{Referências}

Bonham-Carter G.F. 1994. Geographic Information Systems for Geoscientists - Modelling with GIS. Computer Methods in the Geosciences, Vol. 13. $1^{\circ}$ edition, Canada, Pegamon Press, 398p.

Caetano-Chang M.R., 1984. Análise Ambiental e estratigráfica do Subgrupo Itararé (PC) no sudoeste do Estado de São Paulo. Tese de Doutoramento. IG/USP. São Paulo.

Campos H.C.N.S. 1993. Caracterização e cartografia das províncias hidrogeoquímicas do Estado de São Paulo. São Paulo. Tese de Doutoramento, $I G /$ USP 177 p. e 1 mapa

DAEE-UNESP. 1979. Mapa Geológico: divisão faciológica do SuperGrupo Tubarão, escala 1:50.000.

DAEE (Departamento de Águas e Energia Elétrica). 1981a. Estudo de Águas Subterrâneas, Região Administrativa 5 (Campinas), SP. São Paulo, SP. DAEE, $2 v$

DAEE (Departamento de Águas e Energia Elétrica). 1981b. Estudo de Águas Subterrâneas, Região Administrativa 4 (Sorocaba), SP. São Paulo, SP. DAEE, $2 \mathrm{v}$.

Diogo A., Bertachini A.C., Campos H.C.N.S., Rosa R.B.G.S. 1981. Estudo preliminar das características hidráulicas e hidroquímicas do Grupo Tubarão no Estado de São Paulo. In: $3^{\circ}$ Simp. Reg. Geol., Curitiba, PR. Atas. SBG, Curitiba , 1:359-368.

Feyen L., Ribeiro Jr P.J., De Smedt F., Diggle P.J. 2002. Bayesian methodology to stochastic capture zone determination: conditioning on transmissivity measurements. Water Resources Research, 38(9); 3-12

Feyen L., Gomez-Hernandez P.J., Ribeiro Jr P.J., Beven K.J., De Smedt F. 2003. A bayesian approach to stochastic capture zonedelineation incorporating tracer arrival times, conductivity measurements and hydraulic head observations. Water Resources Research. 39(5): 10.

França A.B. \& Potter P.B. 1989. Estratigrafia e ambiente deposicional do Grupo Itararé (Permocarbonífero), Bacia do Paraná (Parte 2). Bol. Geoc. Petrobrás, 3 (1/2): 17-28.

Fúlfaro V.J., Stevaux J.C. Souza Fo E. E., Barcellos J.H. 1984. A Formação Tatuí (P) no Estado de São Paulo. Rio de Janeiro, Cong. Bras. Geol., 22, Anais, v.2, p.711-724.

Harbaugh J.W., Davis J.C., Wendebourg R. 1995. Computing risk for oil prospects: Principles and programs. Computer Methods in the Geosciences, v. 14, USA, Pergamon Press, 452p.
IG/SMA - Instituto Geológico. 1993. Subsídios do meio físico-geológico ao planejamento do município de Capinas (SP). Relatório Técnico IG;SMA, 3v.

IG/SMA - Instituto Geológico. 1995. Subsídios do meio físico-geológico ao planejamento da Porção Média da Bacia do Rio Piracicaba (SP). São Paulo. Relatório Técnico IG/SMA, 4v.

Lopes M.F.C. 1994. Condições de ocorrência de água subterrânea nas bacias dos rios Piracicaba e Capivari. Dissertação de Mestrado, UNICAMP. Campinas, 83p.

Rostirolla S.P. 1996. Avaliação de favorabilidade em exploração: um enfoque metodológico. Tese de Doutoramento IGCE/UNESP. Rio Claro $164 \mathrm{p}$.

Rostirolla S.P. 1997. Alguns aspectos da avaliação de favorabilidade em geologia exploratória. Ver.Brás. Geoc., 27:327-338.

Rostirolla S.P., Mattana A.C., Bartoszeck M.K. 2003. Bayesian assessment of favorability for oil and gas prospects over the Recôncavo basin, Brazil. AAPG Bulletin, 87:647-666.

Stevaux J.C., Souza F E.E., Teixeira J.A., Landim P.M.B. 1987. Sistemas deposicionais do Subgrupo Itararé (P-C) na bacia hidrográfica do baixo Rio Capivari (SP): um modelo para prospecção de água subterrânea. In: Simp. Reg. Geol., 6. Rio Claro, 1987. Atas... Rio Claro, SBG/NSP. V.1, p. 355-374.

Taltasse P.R. 1968. Os fácies hidroquímicos no Estado de São Paulo. In: $22^{\circ}$ Congr. Bras. Geol., Belo Horizonte, MG. Anais ...SBG, Belo Horizonte. I:263-266.

Vidal A.C. 2002. Estudo hidrogeológico do Aqüífero Tubarão na área de afloramento da porção central do Estado de São Paulo. Tese de Doutoramento IGCE/UNESP. Rio Claro-SP 109p.

Yoshinaga-Pereira S. 1996. Proposta de representação cartográfica na avaliação hidrogeológica para o estudo de planejamento e meio ambiente, exemplo da região metropolitana de Campinas-SP. Tese de Doutoramento IG/USP. São Paulo 190p.

Manuscrito A-1494

Recebido em 03 de março de 2004 Revisão dos autores em 15 de setembro de 2005 Revisão aceita em 25 de setenbro de 2005 